\title{
BREVES REFLEXÕES ACERCA DO USO DE IMAGEM DE ATLETA PROFISSIONAL DE FUTEBOL EM JOGOS ELETRÔNICOS
}

\author{
João Mário Estevam da Silva ${ }^{1}$ \\ Erickson Gavazza Marques ${ }^{2}$ \\ Walter Godoy dos Santos Jr. ${ }^{3}$
}

\begin{abstract}
Resumo:
Enquanto componente essencial da personalidade, a proteção da imagem da pessoa sempre mereceu atenção doutrinária e legislativa. Erigido à categoria de direito fundamental imanente ao ser humano, o direito à imagem guarda estreita sincronia com o princípio da proteção da dignidade da pessoa humana. Estabelecido esse pano de fundo, abordaremos temáticas referentes à licença de uso da imagem de atletas profissionais para disponibilização em jogos eletrônicos. Pontuaremos a eficácia e a extensão do consentimento do titular do direito, bem como as relações jurídicas entre o atleta, entidade desportiva e empresas de tecnologia desenvolvedoras dos games. Por fim, traçaremos pontos de estímulo às reflexões jurídicas pertinentes a casos concretos.
\end{abstract}

Palavras-chave: Direito de personalidade - licença de uso da imagem - atletas profissionais jogos eletrônicos - games

\section{A BRIEF REFLECTION ON THE USE OF PROFESSIONAL SOCCER ATHLETE IMAGE IN ELECTRONIC GAMES}

\begin{abstract}
:
The protection of the right of image has always deserved doctrinal and legislative attention as an essential component of the personality. The right of image is intimately related to the principle of protecting dignity, since it is spouted as a fundamental right inherent to human beings. Having established this perspective, we will discuss themes related to the license for the use of image of professional athletes for availability in electronic games. We will record the effectiveness and extent of the consent of the rightholder, as well as the legal relationship between the athlete, sports entity and technology companies that develop the games. Finally, we will draw up points of encouragement to legal reflections pertinent to individual cases.
\end{abstract}

Key words: Personality - dignity - image right / right of image - license - professional athletes - technology companies - electronic games.

\footnotetext{
${ }^{1}$ Juiz de Direito no Tribunal de Justiça de São Paulo. Especialista em Direito Processual Civil pela Escola Paulista da Magistratura. Doutorando em Direito Empresarial pela Universidade Nove de Julho. Foi Professor no Curso de Direito Constitucional do Centro Universitário Módulo, do Grupo Cruzeiro do Sul.

${ }^{2}$ Desembargador do Tribunal de Justiça de São Paulo. Doutorado pela Universidade de São Paulo. Mestrado em Direito pela Université de Paris II (Pantheon-Assas). Especialização pela Faculdade de Medicina da Universidade de São Paulo. Especialização pela Faculdade de Direitro da Universidadse de Paris II (pantheonAssas). Professor nos Cursos de Mestrado e Doutorado da Universidade Nove de Julho.

${ }^{3}$ Graduado, Mestre e Doutor em Direito pela USP. Professor do curso de Pós Graduação em Direito da Universidade Nove de Julho. Professor e Coordenador de cursos na Escola Paulista da Magistratura. Juiz de Direito no Tribunal de Justiça de São Paulo, convocado para auxiliar o Ministro Luiz Fux na Presidência do CNJ.
} 


\section{INTRODUÇÃO}

O presente estudo tem por objetivo analisar os contornos e os reflexos jurídicos da utilização da imagem e demais dados característicos de atletas profissionais por empresas desenvolvedoras de jogos eletrônicos ou produtos digitais.

Esse tema é altamente relevante, pois as empresas de videogames prosseguem no aprimoramento de inteligência artificial (artificial intelligence - "AI"), no desenvolvimento de novos softwares e sistemas de hardwares, e em espaços tecnológicos ainda mais avançados como os de realidade virtual (virtual reality - "VR") e de realidade aumentada (augmented reality - “AR”).

Nesse passo, a utilização de imagens retratando a efígie, a performance esportiva e demais elementos de identificação da pessoa de renomados e consagrados atletas representa importante elemento de diferenciação mercadológica e de estímulo ao consumidor, especialmente diante do crescimento em larga escala da demanda por jogos eletrônicos, de modo a tornar-se um fenômeno de proporções globais.

Portanto, considerando que le jeu vidéo est également très singulier d'un point de vue économique ${ }^{4}$, é inevitável o enfrentamento de questões correlatas e atinentes à tutela do direito à imagem de personalidades públicas, notadamente de atletas profissionais como os jogadores de futebol, alvo deste trabalho.

\section{BREVES CONSIDERAÇÕES A RESPEITO DA DIGNIDADE DA PESSOA}

\section{HUMANA}

A proteção constitucional da dignidade da pessoa humana é estabelecida como um dos princípios fundamentais que alicerçam o ordenamento jurídico brasileiro (art. $1^{\circ}$, inciso

\footnotetext{
${ }^{4}$ Tradução livre: "o videogame também é muito singular do ponto de vista econômico", conforme se extrai do artigo de Maître Antoine Casanova (2021, p. 137), com o seguinte título "Droit d'auteur et jeu vidéo", publicado na revista: La propriété intellectuelle \& la transformation numérique de l'économie, do INPI - La propriété intellectuelle et la transformation numérique de l'économie.
} 
III, da CF/88), e cuja carga valorativa irradia efeitos para conformar toda legislação infraconstitucional pertinente (artigos $1^{\circ}$, inciso III, e $5^{\circ}$, da Constituição Federal de $1988^{5}$ ).

Muito embora não exista uma concepção precisa e definitiva quanto ao significado de dignidade, é perfeitamente possível compreendê-la como o conjunto de valores mínimos necessários à preservação do núcleo essencial ${ }^{6}$ e existencial da pessoa humana. Logo, a tarefa de compreender o sentido de dignidade requer adaptabilidade conceitual e técnicas interpretativas eficientes à promoção da sua efetividade. ${ }^{7}$

Partindo-se da premissa de que a norma constitucional é dotada de supremacia, sua posição no vértice do ordenamento jurídico aloca seus valores e princípios como parâmetros de observância obrigatória, que devem nortear as atividades do intérprete do direito. ${ }^{8}$

Essa força de conformação não se exaure no mero juízo de coerência ou de compatibilidade das normas infraconstitucionais com a Constituição Federal. A harmonia que se espera do sistema é solução que merece primazia ${ }^{9}$, justamente para tornar fértil o campo de concretização dos direitos e garantias fundamentais.

Nesse passo, a unidade da constituição exsurge como um dos mais importantes princípios de estruturação, pois torna factível a higidez do sistema jurídico ${ }^{10}$. Além disso, a

\footnotetext{
5 “Art. $1^{\circ}$ A República Federativa do Brasil, formada pela união indissolúvel dos Estados e Municípios e do Distrito Federal, constitui-se em Estado Democrático de Direito e tem como fundamentos: [...] III - a dignidade da pessoa humana;"
}

"Art. $5^{\circ}$. Todos são iguais perante a lei, sem distinção de qualquer natureza, garantindo-se aos brasileiros e aos estrangeiros residentes no país a inviolabilidade do direito à vida, à liberdade, à igualdade, à segurança e à propriedade, nos termos seguintes:

$\mathrm{V}$-é assegurado o direito de resposta, proporcional ao agravo, além da indenização por dano material, moral ou à imagem;

$\mathrm{X}$ - São invioláveis a intimidade, a vida privada, a honra e a imagem das pessoas, assegurando o direito à indenização pelo dano material ou moral decorrente de sua violação."

${ }^{6}$ O princípio da proteção do núcleo essencial, previsto nas Constituições da Alemanha (art.19, II, de 1949) e de Portugal (art.18 , III, de 1976), não foi contemplado em nossa Constituição Federal de 1988, conforme bem constatou Gilmar Ferreira Mendes (2012, p. 241).

${ }^{7}$ A dignidade se refere a valores intrínsecos à própria existência da pessoa humana.

${ }^{8}$ Sabemos que a interpretação constitucional é pautada em critérios e princípios bem definidos pela hermenêutica, ainda que não expressamente previstos na Constituição Federal.

9 Maria Helena Diniz (1997, p. 123-125) enfatiza o "sistema é o modo analítico de ordenar a realidade logicamente", e complementa no sentido de que "o direito não é um sistema, é uma realidade que pode ser estudada sistematicamente pela ciência do direito", cuja coerência é necessária "ante a impossibilidade de existirem preceitos infraconstitucionais antagônicos à Lei Maior". Não é demais trazer à lume o ensinamento de Norberto Bobbio (1996, p. 8), para o qual as normas jurídicas não existem isoladamente, mas compõe um conjunto coordenado na forma de um sistema normativo, necessariamente coerente e harmônico.

${ }^{10}$ Gilberto Bercovici (2000, p. 97) bem afirma que "a Constituição deve sempre ser entendida e interpretada em sua unidade, tendo em vista que todas as suas normas estão em mútua interação e dependência.” 
potência da efetividade deve corresponder às expectativas e satisfazer, in concreto, as necessidades relacionadas aos valores mais sensíveis e caros da nossa ordem jurídica, tal como o princípio da proteção da dignidade da pessoa humana.

Naquilo que é pertinente ao princípio basilar da dignidade da pessoa humana, cumpre observar que a sua tutela irradia valores e efeitos, cujo feixe constitui inafastável mandamento de otimização dos direitos inerentes à personalidade. ${ }^{11}$

Assim, para arrematar essas premissas, buscamos no escólio de Konrad Hesse (1991, p. 16-18) a constatação de que a força normativa de uma constituição decorre justamente da eficácia pretendida pela realidade. Logo, a tão almejada efetividade da dignidade e da personalidade deve ser aferida "com base na natureza singular do presente", a partir da qual se procura "construir o futuro". 12

\section{DOS DIREITOS DA PERSONALIDADE}

De acordo com Pontes de Miranda (2012, p. 255), o direito de personalidade é fonte da qual irradiam direitos sensíveis, tais como o à vida, liberdade, honra, integridade e igualdade. Por força do caráter essencial desses bens jurídicos, o espectro jurídico da personalidade é marcado pela irrenunciabilidade e inalienabilidade.

Evidentemente, dignidade e personalidade estão relacionadas em grau de complementariedade, pois ambas se entrelaçam no âmbito do já referido núcleo essencial e

11 É consabido que o ordenamento não é composto apenas por regras, mas também por princípios de harmonização do sistema, a revelar a importância de se conhecer e distinguir direitos fundamentais de princípios fundamentais. E conforme bem ponderado por Manuel Gonçalves Ferreira Filho, é possível que "dos direitos fundamentais se podem inferir princípios" (ALEXY, 2015, p. 417).

12 “Quanto mais o conteúdo de uma Constituição lograr corresponder à natureza singular do presente, tanto mais seguro há de ser o desenvolvimento de sua força normativa. Tal como acentuado, constitui requisito essencial da força normativa da Constituição que ela leve em conta não só os elementos sociais, políticos, e econômicos dominantes, mas também que, principalmente, incorpore o estado espiritual (geistige situatión) de seu tempo. Isso lhe há de assegurar, enquanto ordem adequada e justa, o apoio e a defesa da consciência geral" (HESSE, 1991, p. 20) Mas Hesse acrescenta que "uma mudança das relações fáticas pode — ou deve — provocar mudanças na interpretação Constituição" (HESSE, 1991, p. 23). E complementa "Em outros termos, o Direito Constitucional deve explicitar as condições sob as quais as normas constitucionais podem adquirir a maior eficácia possível, propiciando, assim, o desenvolvimento da dogmática, e da interpretação constitucional. Portanto, compete ao Direito Constitucional realçar, despertar e preservar a vontade dê" Constituição (Wille zur Verfassung), que, indubitavelmente, constitui a maior garantia de sua força normativa". 
existencial da pessoa humana. Em síntese, são elementos intrinsicamente conectados "à própria essencialidade do ser", conforme bem apontou Carlos Alberto Bittar (1999, p. 47). ${ }^{13}$

A dignidade e a personalidade são elementos essenciais e devem ser compreendidos como componentes de estruturação do ser humano. Este, por sua vez, deve ser considerado em suas multifacetadas dimensões, tais como: física, moral e intelectual.

Com ênfase na personalidade, Maria Helena Diniz (2015, p. 130) é precisa ao afirmar que tal elemento não é propriamente um direito, mas sim fonte e resultado da concretização de vários outros direitos pertinentes à essencialidade humana ${ }^{14}$. E é com base nessa compreensão que prosseguimos.

De fato, a personalidade é composta por um feixe de bens jurídicos que encontram na dignidade sua fonte e destino. A vocação desses bens é proporcionar ao indivíduo a concretização da própria dignidade, em um processo que se retroalimenta.

A compreensão da complementariedade e sincronia é ínsita à própria liberdade e à igualdade entre as pessoas, desde o seu nascimento e durante toda a sua existência, conforme preconizado na Declaração dos Direitos do Homem e do Cidadão de $1789 .^{15}$

No âmbito dos direitos de personalidade inexistem barreiras de tempo, fronteiras ou territórios, conforme consagrado na Declaração Universal dos Direitos Humanos de $1948^{16}$. E segundo extrai-se do respectivo preâmbulo, não se trata de conceder dignidade à pessoa, pois a dignidade é inerente ao ser humano. O que há é a declaração da dignidade como atributo inerente e fundamental à liberdade, à justiça e à paz no mundo. ${ }^{17}$

\footnotetext{
${ }^{13}$ Expressão muito bem empregada por Carlos Alberto Bittar (1999, p. 47). Valiosas também são as palavras de Antônio Chaves (1982, p. 435), segundo o qual "existe um conjunto de normas que podem ser rastreadas em todas as legislações, quando não explícitas, nelas contidas implicitamente e que são tão essenciais que mal de concebem separada do próprio conceito de civilização e de acatamento à pessoa humana. O respeito à vida e aos demais direitos correlatos, decorre de um dever absoluto, por sua própria natureza, ao qual a ninguém é lício desobedecer".

${ }^{14}$ Segundo Manuel Gonçalves Ferreira Filho (2011, p. 417), a mera distinção entre direitos e princípios pode não ser decisiva no processo de solução de crises, na medida em que podem ser extraídos princípios dos próprios direitos fundamentais.

${ }^{15}$ Déclaration des Droits de l'Homme et du Citoyen: "Article $1^{\text {er }}$ - Les hommes naissent et demeurent libres et égaux en droits. Les distinctions sociales ne peuvent être fondées que sur l'utilité commune". Tradução em português: "Artigo $1^{\circ}$ - Os homens nascem e permanecem livres e iguais em direitos. Distinções sociais só podem ser baseadas em utilidade comum." (CONSEIL CONSTITUTIONNEL, 1789)

${ }^{16}$ Universal Declaration of Human Rights: "Article 6 - Everyone has the right to recognition everywhere as a person before the law". Tradução: "Artigo $6^{\circ}$ - Todos os indivíduos têm direito ao reconhecimento em todos os lugares da sua personalidade jurídica." (UNITED NATIONS, 1948)

${ }^{17}$ Preamble: "Whereas recognition of the inherent dignity and of the equal and inalienable rights of all members of the human family is the foundation of freedom, justice and peace in the world" (UNITED NATIONS, 1948)
} 
Nesse diapasão, o âmbito da personalidade do indivíduo insere-se no rol dos direitos fundamentais, e muito embora sejam dotados de conceituação abrangente ${ }^{18}$, os direitos de personalidade mereceram tutela jurídica específica. A propósito, a dignidade da pessoa humana é o amálgama entre os direitos fundamentais e de personalidade.

Evidentemente, a proteção da dignidade humana estabelece importantes parâmetros de expectativas de $\operatorname{condutas}^{19}$, permeando as mais diversas atividades privadas e públicas do indivíduo. Por isso, a dignidade e a personalidade são dotadas de considerável elasticidade conceitual, justamente para imprimir seus efeitos concretos no complexo cenário das relações humanas. $^{20}$

Portanto, é possível concluir que a dignidade e a personalidade são imanentes à condição da existência humana, e que compõem um feixe sincrônico de forças normativas capazes de influir diretamente nas forças que impulsionam o desenvolvimento econômico, social, cultural e político da humanidade. ${ }^{21}$ Daí a importância de respeitar-se a personalidade

\begin{abstract}
${ }^{18}$ Consoante bem destacado pelo ilustre jurista J. J. Gomes Canotilho (1997, p. 390), segundo o qual, in verbis: "abarcam certamente os direitos de estado (por ex.: direito de cidadania), os direitos sobre a própria pessoa (direito à vida, à integridade moral e física, direitos à privacidade), os direitos distintivos da personalidade (direito à identidade pessoal, direito à informática) e muitos direitos de liberdade de expressão). Tradicionalmente, afastavam-se dos direitos de personalidade os direitos fundamentais políticos e os direitos a prestações por não serem atinentes ao ser como pessoa".

${ }^{19}$ Luís Roberto Barroso (2003, p. 25-65) destacou que "o discurso acerca dos princípios, da supremacia dos direitos fundamentais e do reencontro com a Ética - ao qual, no Brasil, se deve agregar o da transformação social e o da emancipação - deve ter repercussão sobre o ofício dos juízes, advogados e promotores, sobre a atuação do Poder Público em geral e sobre a vida das pessoas". E prossegue: "Em diversas situações, inclusive e notadamente nas hipóteses de colisão de normas e de direitos constitucionais, não será possível colher no sistema, em tese, a solução adequada: ela somente poderá ser formulada à vista dos elementos do caso concreto, que permitam afirmar qual desfecho corresponde à vontade constitucional".
\end{abstract}

${ }^{20}$ Ainda nesse ponto, André Ramos Tavares (2009, p. 88-89) destaca: "A interpretação das normas em geral e, em particular, das constitucionais, como visto, permite se promova a evolução material. Trata-se de uma orientação inafastável. É necessário buscar um equilíbrio entre perenidade e mutabilidade. A interpretação evolutiva é a operação destinada a reconstruir o direito dinamicamente, na medida das exigências cambiantes que a realidade social manifesta. Só pode falar em intepretação evolutiva dentro da opção conceitual de constituição aberta como é o caso da brasileira"

${ }^{21}$ É o que se extrai da Declaração sobre o Direito ao Desenvolvimento, adotada pela Resolução 41/128 da Assembléia Geral da ONU, em 04 de dezembro de 1986, que proclama em seu artigo $1^{\circ}$, parágrafo primeiro, in verbis: "§1. O direito ao desenvolvimento é um direito humano inalienável, em virtude do qual toda pessoa e todos os povos estão habilitados a participar do desenvolvimento econômico, social, cultural e político, para ele contribuir e dele desfrutar, no qual todos os direitos humanos e liberdades fundamentais possam ser plenamente realizados" (NACIONES UNIDAS, 1986). Nessa mesma toada, podemos destacar a Declaração e Programa de ação de Viena, adotada em 25 de junho de 1993 pela Conferência Mundial sobre Direitos Humanos, que se realizou em Viena, Áustria, de 14 a 25 de junho de 1993. De acordo com o item 5 do documento, in verbis: "Todos os direitos humanos são universais, indivisíveis, interdependentes e interrelacionados. (...)". E mais, pois de acordo com o respectivo item 8 , in verbis: "A democracia, o desenvolvimento e o respeito pelos direitos humanos e liberdades fundamentais são interdependentes e reforçam-se mutuamente." (MINISTÉRIO PÚBLICO, 1993). 
do indivíduo, em quaisquer de suas manifestações, inclusive na exploração da imagem de atletas em jogos eletrônicos, de maneira a se reservar a dignidade da pessoa.

\section{DO DIREITO DE IMAGEM}

Os direitos de personalidade são, por sua essência, intransmissíveis e irrenunciáveis, mas o seu exercício pode ser voluntariamente limitado pelo titular ${ }^{22}$. E o ponto central a ser explorado é a especificidade dessa limitação ${ }^{23}$.

A importância disso decorre da impossibilidade de redução dos atributos intrínsecos à essência da pessoa humana, razão pela qual eventuais limitações não poderão emudecer ou vulnerar as condições estruturantes da pessoa (artigo 5, incisos V, X e XXVIII, alínea "a", da Constituição Federal de 1988).

E, considerados tais aspectos, verificamos a relevância do direito de imagem no cenário tecnológico, à qual se convencionou chamar de "e-sports", e mais precisamente a importância da tutela dos direitos de personalidade de atletas profissionais no âmbito dos jogos eletrônicos.

Com efeito, inspira cautela e medidas de proteção a exploração quase fidedigna da imagem de atletas, especialmente porque disponibilizadas em atividades atípicas, como as dos jogos eletrônicos, que proporcionam ao consumidor ou usuário dos games encenações genuínas a partir de representações muito fiéis à realidade.

Se, de um lado, as expectativas por uma experiência inovadora e envolvente suplantam a mera concepção de consumo de jogos eletrônicos, de outro lado a performance, acompanhada de imagens quase reais de atletas, compõem verdadeiro elemento diferencial para as finalidades lucrativas.

$\mathrm{O}$ acentuado realismo e as experiências de quase imersão definem cada vez mais as preferências e as exigências do mercado consumidor, o que impulsiona as empresas desenvolvedoras de jogos a agregar elementos de diferenciação para garantir ou ampliar sua fatia em um mercado altamente competitivo.

\footnotetext{
${ }^{22}$ Conforme art.11 do Código Civil de 2002: "Art. 11. Com exceção dos casos previstos em lei, os direitos da personalidade são intransmissíveis e irrenunciáveis, não podendo o seu exercício sofrer limitação voluntária." (BRASIL, 2002)

${ }^{23}$ Consoante orientação contida no Enunciado n. 4 da I Jornada de Direito Civil do Conselho da Justiça Federal. (CJF, 2012)
} 
Não remanescem dúvidas quanto ao poder das experiências cognitivas e emocionais proporcionadas aos consumidores por meio de recursos de imagem tão avançados e fidedignos, cujos resultados representam poderoso incremento de vendas e geração de lucros. $^{24}$

Acrescente-se que milhões de "gamers" ao redor do mundo estão virtualmente engajados pela oportunidade de compartilhamento artificial de habilidades e poderes que lhes são inacessíveis no mundo real. Alguns até mesmo conseguem construir fama no mundo virtual, destacando-se entre competidores profissionais.

É oportuno destacar a relevância do estudo "Video Games in the 21st Century: The 2020 Economic Impact Report”, de cujo teor se extrai que, apenas no ano de 2019, a indústria norte americana de videogames gerou cerca de US\$ 90,3 bilhões, bem como uma arrecadação tributária anual de cerca de US\$12,6 bilhões. (ESA, 2019)

Efetivamente, a utilização da imagem de atletas consagrados proporciona às desenvolvedoras de games poderoso apelo mercadológico, razão pela qual devem ser estabelecidos contornos claros quanto aos atos de disposição com vistas à máxima efetividade da tutela dos direitos de personalidade e de imagem dos jogadores profissionais.

Observe-se que a imagem e demais atributos do atleta profissional são elementos relacionados às expectativas do mercado consumidor de games, fato que acaba evidenciando ainda mais o protagonismo do atleta em sua própria atividade profissional típica. Nesse sentido, o esportista poderá incrementar e valorizar, por meio da atividade atípica, a sua imagem-atributo.

Porém, a exploração econômica da imagem do atleta em nada se confunde com a mera veiculação de notícias ou informações de interesse público, pois a atividade da desenvolvedora dos games é empresarial e com fins lucrativos, arrimada nos atributos

\footnotetext{
${ }^{24}$ Esse incremento nas vendas decorre da expectativa do consumidor, justamente impulsionada pela utilização de personalidades consagradas. É o desenvolvimento ou exploração de um modelo de comportamento de consumo, a partir da utilização de elementos próprios de psicologia cognitiva e microeconomia. É o que bem pontuou Richard Thaler (1985); no artigo "Mental Accounting and Consumer Choice". Versão original em inglês: "A new model of consumer behavior is developed using a hybrid of cognitive psychology and microeconomics. The development of the model starts with the mental coding of combinations of gains and losses using the prospect theory value function. Then the evaluation of purchases is modeled using the new concept of "transaction utility." The household budgeting process is also incorporated to complete the characterization of mental accounting. Several implications to marketing, particularly in the area of pricing, are developed". Ainda a respeito do tema, Soutar e Sweeney ponderaram que a respeito do modelo de tomada de decisão do consumidor. Segundo eles, o valor percebido do produto é afetado pelas experiências, porquanto esse valor "deve ser visto como parte de um processo contínuo". Trecho original: "perceived product value should be viewed as a part of a continuous process".
} 
qualificativos do indivíduo. Assim, a utilização da imagem dos atletas exige prévia, explícita e específica autorização por meio de contrato de licença de uso de imagem. Somente assim será seguro afirmar a existência inequívoca do consentimento e os exatos contornos da eficácia da sua autorização.

Nesse passo, a tutela da imagem do atleta encontra sua gênese na proteção geral inerente aos direitos de personalidade e de dignidade, e alcança regras próprias atinentes ao desporto brasileiro. ${ }^{25}$

\section{DA EXPLORAÇÃO DO DIREITO DE IMAGEM DO ATLETA}

\section{PROFISSIONAL DE FUTEBOL}

Consoante já demonstrado, o direito de imagem pode estar relacionado com a dimensão das qualificações e perfis pessoais do atleta profissional, ou pode guardar correspondência com as peculiaridades dos contratos de direito desportivo.

De um modo geral, os atos de disposição voluntária do exercício do direito de imagem estão circunscritos ao alcance das cláusulas pactuadas entre o atleta e a entidade desportiva, não se admitindo interpretação extensiva.

A interpretação restritiva do contrato de licença de uso de imagem $^{26}$ encontra justificativa na própria natureza do bem jurídico, cujo uso é alvo de disposição. Não é demais reprisar que o direito de imagem é, em si, personalíssimo e inalienável, devendo-se ressaltar que o seu exercício poderá ser transacionado com reservas.

Nesse passo, eventual divulgação da imagem do atleta deve estar explícita e irremediavelmente pautada nas cláusulas do ato de disposição, não servindo eventual contraprestação econômico-financeira como mecanismo para relativizar o rigor da tutela legal. $^{27}$

\footnotetext{
${ }^{25}$ São parâmetros os preceitos da educação, liberdade, da isonomia e da democratização acesso às atividades desportivas sem quaisquer distinções ou formas de discriminação. Conf. arts. $1^{\circ}$ e $2^{\circ}$, incisos III, IV e VIII, da Lei n 9.615, de 24 de março de 1998.

${ }^{26}$ Bastante oportuno se faz o alerta quanto ao equivocado o uso da expressa cessão de direito de imagem, pois o correto é o emprego do termo licença de uso.

${ }^{27}$ A título de exemplo, o direito de arena possibilita a veiculação da imagem na transmissão dos jogos, rendendo ao atleta uma fração do percentual negociado entre a entidade desportiva e os canais de divulgação. Seja como for, também é importante frisar que tais relações jurídicas são de natureza civil e, por isso, não se confundem com a figura e as especificidades do contrato de trabalho desportivo.
} 
É preciso compreender a preponderância da vontade do titular do direito quanto aos limites da divulgação da sua imagem, seja ela atrelada a produtos ou serviços no mercado publicitário e de consumo, ou por meio da veiculação da imagem na transmissão dos jogos nos canais de divulgação.

Isso garante ao titular do direito todos os meios idôneos previstos em lei para a tutelar seus interesses na hipótese de exasperação não autorizada dos limites impostos à exploração do bem jurídico. Em razão disso, os pactos para a disposição do exercício do direito à imagem não comportam elasticidade indevida, devendo ser restritivamente interpretados (tudo o que não estiver expressamente autorizado, estará automaticamente proibido).

A dimensão material dos direitos de personalidade nos remete ao campo da responsabilidade civil, estando o faltoso sujeito aos rigores da lei e ao dever de reparação, independentemente da necessidade de se provar o dano, cuja ocorrência é passível de presunção. ${ }^{28}$ É o chamado dano in re ipsa, cujo prejuízo existe independentemente de prova nesse sentido.

Em breves linhas, merecem ser estimuladas condutas pautadas nos deveres de lealdade e boa-fé, bem como nos princípios constitucionais da prevenção e da precaução. Na hipótese de descumprimento, impõe-se a responsabilização do infrator consolada nos mecanismos de reparação ou de satisfação pecuniária equivalente.

É preciso compreender que o contrato de licença de uso de imagem $^{29}$ não se confunde com o contrato especial de trabalho desportivo, nem tampouco com o direito de arena. Por isso, não basta a mera anuência dos sindicatos e das entidades desportivas como meio de suprir eventual ausência de manifestação expressa do atleta.

Tal conclusão encontra amparo na Lei $n^{\circ}$ 9.615, de 24 de março de 1998, que institui normas gerais sobre desporto. Consoante o previsto no artigo 87-A, "o direito ao uso da imagem do atleta pode ser por ele cedido ou explorado, mediante ajuste contratual de natureza

\footnotetext{
${ }^{28}$ Nesse sentido, em outubro de 2009, o Superior Tribunal de Justiça editou a súmula n. 403 consolidando entendimento de que "independe de prova do prejuízo a indenização pela publicação não autorizada da imagem de pessoa com fins econômicos ou comerciais".

${ }^{29}$ Urge bem distinguir as expressões "cessão de direito de imagem" e "licença de uso". Enquanto na cessão o titular abre mão, em definitivo, total ou parcialmente, do seu direito exclusivo, na licença ele continua senhor do seu direito sobre a imagem, permitindo o uso por terceiros apenas temporariamente, sendo que ele retoma seu direito exclusivo tão logo expire a licença.
} 
civil e com fixação de direitos, deveres e condições inconfundíveis com o contrato especial de trabalho desportivo."

Portanto, é imprescindível a manifestação expressa e inequívoca do consentimento do atleta, não bastando, para tanto, a existência de contrato especial de trabalho desportivo, cujos limites ordinários não bastam para autorizar a exploração da imagem do esportista em qualquer outro produto ou atividade diversa.

Observe-se que as atividades típicas inerentes ao contrato especial de trabalho e a transmissão dos jogos envolvem a divulgação de informações inerentes à própria atividade desportiva, que, por vezes, pode influir no legítimo exercício de alguns direitos dentre os quais o de arena. Explicamos: é que:

[...] sob o manto do direito á informação, alguns abusos podem ser cometidos, como, por exemplo, retransmissões longas do espetáculo esportivo, que iriam muito além dos gols e dos melhores momentos. Segundo alguns críticos dos abusos do direito à informação, em muitos casos, essas retransmissões poderiam, de certa forma, fazer concorrência com a retransmissão do evento propriamente dito, o que não seria justo para com o empreendedor audiovisual que adquiriu, mediante uma contrapartida financeira, o direito exclusivo de divulgar as imagens. (GAVAZZA MARQUES, 2007, p. 145)

Por conseguinte, a eventual existência de cláusula no contrato especial de trabalho esportivo autorizando o uso do direito de imagem e demais dados, informações ou atributos do atleta, impõe aos contratantes o dever de respeitar a disposição contratual nos exatos limites da concordância do jogador.

São esses os parâmetros mínimos que devem nortear as relações jurídicas envolvendo a utilização de imagem de atletas na disponibilização de jogos eletrônicos. Aliás, a dinamicidade da evolução tecnológica impõe ao Direito novos desafios relacionados à solução concreta de novas demandas, pois provoca reflexões e ponderações acerca do que é realmente necessário e efetivo à preservação dos direitos fundamentais ${ }^{30}$.

Questão interessante envolve os limites da utilização da imagem do atleta profissional a partir do contrato de licença de marcas celebrado entre a empresa

\footnotetext{
${ }^{30}$ Ainda nesse ponto, a cautela deve pautar condutas e soluções, pois o desenvolvimento de produtos digitais encontra inspiração a partir de elementos característicos de pessoas consagradas em suas atividades profissionais. A título de exemplo, o dever de coerência e de razoabilidade impõe reflexões a respeito das consequências jurídicas nas hipóteses de singela representação gráfica ou de composição de personagem fictício, ainda que a partir de inspiração em dados ou informações de atletas profissionais reais.
} 
desenvolvedora dos jogos eletrônicos e a entidade desportiva em que atua o atleta. Em regra, o contrato de licença é relação jurídica limitada aos contratantes, cujo objeto é a exploração do direito de arena com ênfase no espetáculo desportivo (Artigo 42 da Lei nº 9.615/1998). Assim, a inexistência de cláusula específica não autorizaria a exploração do direito de imagem do atleta em atividades, produtos ou serviços distintos.

Outro ponto merecedor de atenção seria a eventual suficiência da autorização expressa do atleta no corpo do contrato especial de trabalho desportivo, com vistas a possibilitar, sem a necessidade de nova e específica autorização, a divulgação das suas imagens em produtos diversos. Nesse caso, respeitados entendimentos em sentido contrário, parece-nos que a preexistência de autorização, por si só, não torna dispensável nova manifestação de consentimento expressa do titular do direito.

Com o escopo de provocar e subsidiar reflexões, importa salientar que a eventual cláusula inserida em contrato especial de trabalho possui, por sua natureza, extensão limitada às atividades típicas do atleta, abarcando àquelas outras inerentes à entidade desportiva no exercício do direito de divulgação do evento esportivo.

Nesse passo, seria perfeitamente questionável a validade e a adequação do uso da sua imagem do atleta em atividades não típicas e estranhas ao contrato especial de trabalho desportivo. Em outras palavras, tais práticas poderiam materializar o indevido alargamento dos efeitos decorrentes da declaração de vontade do atleta.

Sobreleva destacar que o contrato de imagem é de natureza civil, pactuado entre a entidade desportiva e o atleta profissional. E ainda que o atleta se faça representar por meio de representante legal, ou mesmo por pessoa jurídica que detenha seus direitos sobre a imagem, a sua manifestação de vontade deve ser expressa.

Logo, não havendo no contrato especial de trabalho esportivo cláusula expressa quanto à extensão da licença de direito, ou mesmo quanto à possibilidade de novas licenças, a solução adequada seria atribuir ao contrato interpretação e extensão restritivas.

$\mathrm{Na}$ mesma ordem de raciocínio, eventual dispensa de novas autorizações expressas e específicas por parte do atleta poderia implicar ausência de encadeamento lógico-jurídico, fulminando a validade dos atos de disposição posteriores. Seria o desfecho dado à divulgação ou utilização não autorizada da imagem do atleta em atividades atípicas, tais como em jogos eletrônicos. 
Com ênfase na natureza personalíssima do direito de imagem, e na excepcional possibilidade de disposição do seu exercício, poder-se-ia indagar se eventual interpretação extensiva da autorização manifestada pelo atleta implicaria redução do próprio direito de dispor dos componentes econômicos do direito de imagem.

E tal reflexão é de curial importância, pois abriria espaço para argumentos quanto à possibilidade de autorização tácita do atleta, a sugerir suposta outorga de poderes à entidade desportiva para deliberar, em nome do atleta, os traços econômicos da exploração da imagem em atividades atípicas.

Porém, a excepcionalidade e a especificidade do exercício do direito personalíssimo obstam qualquer possibilidade de novos atos de disposição desprovidos de autorização expressa. Logo, não seria possível a hipótese de autorização tácita à entidade desportiva, pois isso significaria legitimar atos de terceiros estranhos às funções típicas do contrato especial de trabalho desportivo. Além disso, a ausência da manifestação expressa do atleta quanto ao novo ajuste fulminaria a validade deste e de todos os atos posteriores.

Enfaticamente, a ausência de liame obrigacional expresso entre o atleta e a entidade desenvolvedora dos jogos eletrônicos configura clara violação do disposto no art. 87-A da Lei 9.615/98. Por consequência, o atleta poderia formular pedido indenizatório ou reparatório por danos sofridos em decorrência da exploração não autorizada, pois não se está diante de conflito entre direitos fundamentais, como ocorreria no caso dos direitos de imagem e de liberdade de expressão e de imprensa.

Em síntese, é imprescindível à validade dos atos de disposição a preexistência de autorizações idôneas e legítimas fornecidas pelo atleta titular do direito. Sem isso, o encadeamento de atos não poderá persistir, e as empresas desenvolvedoras dos jogos não poderão utilizar as informações pertinentes ao atleta. Com efeito, nem mesmo poderão nutrir expectativa de direito em relação ao jogador que permanecera temporariamente inerte diante do uso indevido da sua imagem.

Repita-se que tais questões envolvem a expressividade econômica dos atributos de identificação do atleta, e o seu poder de diferenciação mercadológica capaz de favorecer as empresas desenvolvedoras. O valor econômico da identidade do atleta justifica tanto a proteção da esfera jurídica do titular quanto a vedação do enriquecimento sem causa daquele que indevidamente se beneficia da exploração não autorizada (FORBES, 2016) 


\section{CASUÍSTICA}

Tornaram-se públicas diversas demandas judiciais a respeito da temática ora tratada, notadamente porque certas empresas desenvolvedoras disponibilizaram milhões de acessos a jogos esportivos eletrônicos contendo imagens ou demais atributos de atletas, especialmente relacionados ao futebol.

A título de exemplo, foram submetidas ao Poder Judiciário questões relativas a pagamentos efetuados diretamente à Federação Internacional dos Jogadores Profissionais de Futebol (FIFPro - Fedération Internationale des Associations de Footballeurs Professionnels) que supostamente negocia acordos em diversos países e repassa os valores recebidos às associações nacionais, as quais destinariam tais valores aos jogadores de futebol. Naquilo que é pertinente, a despeito de eventual autorização da Federação Nacional dos Atletas Profissionais de Futebol - FENAPAF, a exploração da imagem dos atletas pela FIFPro não dispensaria a autorização expressa do titular do direito personalíssimo.

Contrariamente ao que pode presumir, ações com tais objetos podem ser identificas desde a década de setenta, merecendo destaque aquela protagonizada pelo renomado jogador inglês Kevin Keegan (WIPO, 2021). Também consta que o alemão Oliver Khan, goleiro mundialmente conhecido, sagrou-se vencedor em ação judicial proposta contra a empresa Electronic Arts, em decorrência da utilização não autorizada dos seus dados no jogo eletrônico FIFA de 2002. ${ }^{31}$ Já no ano de 2009, foi proposta a ação coletiva pela National Collegiate Athletic Association - NACC contra a Electronic Arts, a respeito da utilização de imagens de jogadores universitários amadores nos jogos NCAA Football e NCAA Basketball (THE NEW WORK TIMES, 2010). E, por fim, mais recentemente, podem ser mencionadas ações judiciais propostas por Zlatan Ibrahimovic e outros trezentos atletas contra a empresa EA Sports Fifa, justamente contra a utilização não autorizada das suas imagens no videogame FIFA 21. (IL SOLE 24 ORE, 2020; THE NEW YORK TIMES, 2010)

No cenário brasileiro, chegaram aos Tribunais questões relacionadas aos contratos firmados com a FIFPRO, supostamente a partir de uma cadeia inidônea de cessões do direito de imagem dos atletas. Inferem-se debates relacionados aos contratos firmados entre os atletas

\footnotetext{
${ }^{31}$ Segundo consta, a Electronic Arts não possuía autorização do referido atleta, que igualmente não era membro Federação Europeia de Jogadores de Futebol - FIFPro. A procedência da ação implicou à desenvolvedora a impossibilidade de comercialização do pr oduto na Alemanha. (SPORT BIBLE, 2020)
} 
e os clubes como autorização do uso da imagem, e as cessões das imagens pelos clubes violaram o disposto no art. 87-A, caput, da Lei n ${ }^{\circ}$ 9.615/98. A título de exemplo, o Superior Tribunal de Justiça concluiu pela necessidade do clube firmar com o atleta contrato relativo ao direito de imagem de forma apartada do contrato de trabalho desportivo. (STJ, 2019a)

Com absoluta pertinência, o Colendo Superior Tribunal de Justiça também decidiu que o prazo prescricional relativo ao dano provocado à imagem do atleta deve ser computado desde a data de cada publicação não autorizada, renovando-se a cada nova divulgação não autorizada (STJ, 2019b). Mas não é só, a Corte Superior ainda assentou que a violação do direito independe da produção de novos produtos, considerando que o ilícito civil estará configurado pela a utilização contínua da imagem através da comercialização de versões anteriores dos jogos eletrônicos. (STJ, 2018)

O avanço tecnológico e a crescente demanda pelos jogos eletrônicos e a permanência das pessoas no ambiente virtual certamente darão origem a diversas outras questões afeitas à tutela dos direitos fundamentais.

Nesse sentido, buscando inspiração no caso concreto "Micro Star v. FormGen, Inc.", do Tribunal de Apelações dos Estados Unidos (H20, 1998), podemos destacar questões como a do “creator player" (jogador criador) que poderão suscitar dúvidas a respeito da titularidade do conteúdo livremente composto pelo próprio usuário a partir de elementos gráficos externos ao game ou plataforma, tais como a criação de "skins" ou mesmo a definição de jogabilidades. ${ }^{32}$

\section{CONCLUSÃO}

A tutela e a concretização da dignidade e dos direitos de personalidade demandam soluções cada vez mais consentâneas com as novas questões próprias do desenvolvimento tecnológico.

Não é possível a disseminação de atributos e informações de identificação de uma pessoa natural, ainda que por meio de recursos tecnológicos referentes a jogos eletrônicos, com ênfase, na hipótese sob análise, na atividade profissional do titular do direito de imagem.

\footnotetext{
${ }^{32}$ Indagação interessante se refere à identificação do titular do produto digital alvo da tutela de direitos autorais, pela autoria criativa. Seria ele o "creator player", a empresa desenvolvedora da plataforma ou do jogo eletrônico, ou ambos? Seria o "creator player" mero transformador do jogo originário e, portanto, mero vetor de elementos derivados (art.5 $5^{\circ}$ inciso VIII, alíneas "f" e "g", da LPI)? A propósito, o ponto central seria justamente a existência ou não de criações essencialmente originárias?. (H20, 1998)
} 
É preciso garantir ao indivíduo proteção quanto à coleta e divulgação dos seus dados e informações de identificação, e ainda com mais ênfase o necessário à prevenção para coibir tais utilizações e divulgações não autorizadas.

Efetivamente, são imponíveis em todas as relações jurídicas privadas deveres recíprocos e multilaterais ${ }^{33}$ de respeito à personalidade alheia, cujo objetivo é gerar o maior campo de eficácia possível de direitos fundamentais.

Aliás, a horizontalidade ${ }^{34}$ da eficácia dos direitos fundamentais permite pavimentar o caminho para a efetividade do direito à imagem na amplitude e fluidez das informações no cyberspace e no mercado de produtos e serviços digitais.

A validade dos atos de disposição depende da preexistência de autorizações idôneas, expressas e específicas, para legitimar a utilização das informações, atributos e imagem do atleta titular do direito.

Sem o encadeamento válido entre os atos de autorização e de disposição, a divulgação não poderá persistir, e as empresas desenvolvedoras dos jogos não poderão utilizar as informações pertinentes ao atleta. Nesse cenário, sequer seria possível nutrir expectativa de direito em relação ao jogador que permanecera temporariamente inerte diante do uso indevido da sua imagem.

Diante de todo o exposto, conclui-se que a expressividade econômica dos atributos de identificação do atleta e o poder de diferenciação mercadológica ${ }^{35}$ que tais direitos de imagem são capazes de conferir às empresas desenvolvedoras acentuam a importância da tutela da dignidade, da personalidade e do direito de imagem do atleta profissional de futebol, observando-se, em qualquer hipótese, as balizas da legalidade estrita. (FORBES, 2016)

\footnotetext{
${ }^{33}$ Segundo Ives Gandra da Silva Martins (2012, p. 328), in verbis, "liberdade não significa independência total, isto é, não depender de nada nem de ninguém. A vida em sociedade é, necessariamente marcada pela mútua dependência."

${ }^{34}$ Nelson Rosenvald e Felipe Braga Netto (2018, p. 406) bem sintetizaram que: "não só a aplicação direta dos direitos fundamentais às relações privadas ganha força, mas também - como dissemos antes - a percepção do sistema jurídico como um sistema aberto de princípios normativos. Por isso - mas não só por isso - a sulcada divisão entre direito público e direito privado perde relevância (lembremos que o princípio da dignidade da pessoa humana não conhece setores imunes às suas luzes)."

${ }^{35}$ A respeito desse diferencial mercadológico, e suas implicações no âmbito da concorrência, Alexandre Chwartzmann destaca que, in verbis: "Segundo o artigo 122 da Lei de Propriedade Industrial, podem ser registrados todos os sinais "visualmente perceptíveis": nome da empresa que produz, do jogo, eventualmente até de personagens ou itens do universo dos games. Isso também é importante porque futuramente estes podem ser utilizados para exploração de outros produtos derivados.
} 


\section{REFERÊNCIAS}

ALEXY, Robert. Teoria dos Direitos Fundamentais. Trad. Virgílio Afonso da Silva. 2. ed. São Paulo, Editora Malheiros, 2015.

ALVES, Cleber Francisco. O princípio Constitucional da dignidade da pessoa humana: o enfoque da doutrina social da Igreja. Rio de Janeiro: Renovar, 2001.

ARAÚJO, Luiz Alberto Davi; JUNIOR, Vidal Serrano Nunes. Curso de Direito Constitucional. São Paulo: Saraiva, 1999.

ARAÚJO, Luiz Alberto Davi; JUNIOR, Vidal Serrano Nunes. A proteção Constitucional da própria imagem: pessoa física, pessoa jurídica e produto. Belo Horizonte: Del Rey, 1996.

BARROSO, Luís Roberto; et al. O começo da história: a nova interpretação constitucional e o papel dos princípios no direito brasileiro. Revista da EMERJ, Rio de Janeiro, v. 6, n. 23, 2003.

BARROSO, Luís Roberto; et al. Interpretação e aplicação da Constituição. Fundamento de uma dogmática constitucional transformadora. São Paulo: editora Saraiva, 1996.

BERCOVICCI, Gilberto. Princípio da Unidade da Constituição. Revista de informação legislativa, v. 37, n. 145, p. 95-99, jan./mar. 2000.

BITTAR, Carlos Alberto. Os Direitos de Personalidade, 3. ed., Rio de Janeiro: Ed. Forense Universitária, 1999.

BOBBIO, Norberto. Teoria do Ordenamento Jurídico. Brasília: UNB, 1996.

BONAVIDES, Paulo. Curso de Direito Constitucional. 21. ed., São Paulo: Editora Malheiros, 2007.

BRASIL. [Constituição (1988)]. Constituição da República Federativa do Brasil de 1988. Brasília, DF: Presidência da República. Disponível em:

http://www.planalto.gov.br/ccivil_03/constituicao/constituicao.htm. Acesso em: 16 jul. 2021. 
BRASIL. Lei no 10.406, de 10 de janeiro de 2002. Institui o Código Civil. Disponível em: http://www.planalto.gov.br/ccivil_03/leis/2002/L10406compilada.htm. Acesso em: 23 set. 2021.

CANOtilho, J.J. Gomes. Direito Constitucional e Teoria da Constituição. 4. ed. Coimbra/Portugal: Editora Almedina, 1997.

CASANOVA, Maître Antoine. Droit d'auteur et jeu vidéo. La propriété intellectuelle et la transformation numérique de l'économie. Disponível em:

https://www.inpi.fr/sites/default/files/2_5_extrait_pi_et_transformation_economie_numerique _inpi.pdf. Acesso em 15 ago. 2021.

CHAVES, Antônio. Tratado de Direito Civil. 1ª ed., v. I, tomo I, São Paulo: RT, 1982.

CHAVES, Antônio. Direito à própria imagem. Revista da Faculdade de Direito da

Universidade de São Paulo, v. 67, 1972, p. 45-75. Disponível em:

https://www2.senado.leg.br/bdsf/item/id/180562. Acesso em: 23 set. 2021.

CHWARTZMANN, Alexandre. A propriedade intelectual no mercado de games.

Associação Brasileira da Propriedade Intelectual. Clipping da imprensa Brasília. 27 set. 2021.

\section{CJF - CONSELHO DA JUSTIÇA FEDERAL. Jornadas de Direito Civil I, III, IV e V}

Enunciados Aprovados. Brasília : Conselho da Justiça Federal, Centro de

Estudos Judiciários, 2012. Disponível em: https://www.cjf.jus.br/cjf/corregedoria-da-justicafederal/centro-de-estudos-judiciarios-1/publicacoes-1/jornadas-cej/EnunciadosAprovadosJornadas-1345.pdf. Acesso em: 23 set. 2021.

CLEVE, Clèmerson Merlin Clève, A Fiscalização Abstrata da Constitucionalidade no direito Brasileiro. São Paulo: Revista dos Tribunais, 2000.

CONSEIL CONSTITUTIONNEL. Déclaration des Droits de l'Homme et du Citoyen de 1789. 1789. Disponível em: https://www.conseil-constitutionnel.fr/le-bloc-deconstitutionnalite/declaration-des-droits-de-l-homme-et-du-citoyen-de-1789. Acesso em: 23 set. 2021. 
DINIZ, Maria Helena. Curso de Direito Civil Brasileiro - Volume 1, 32. ed. São Paulo: Saraiva, 2015.

DINIZ, Maria Helena. Norma Constitucional e seus Efeitos. São Paulo: Saraiva, 1997.

DINIZ, Maria Helena. Teoria do Ordenamento Jurídico. Brasília: UNB, 1996.

ESA - ENTERTAINMENT SOFTWARE ASSOCIATION. Video Games in the $\mathbf{2 1}^{\text {st }}$ Century: The 2020 Economic Impact Report. 2019. Disponível em:

https://www.theesa.com/wp-content/uploads/2019/02/Video-Games-in-the-21st-Century2020-Economic-Impact-Report-Final.pdf. Acesso em: 23 dez. 2021.

FELLOUS AVOCATS. Les sportifs au sein des jeux vidéos: droit à l'image....2020. Disponível em: https://fellous-avocats.com/droit-image-sportif-jeux-videos/. Acesso em: 22 set. 2021.

FERREIRA FILHO, Manoel Gonçalves. Curso de direito constitucional. 37ª ed., rev. e atual. São Paulo: Saraiva, 2011.

FORBES. Athletes In Video Games: Balancing Publicity Rights And The First Amendment. 2016. Disponível em: https://www.forbes.com/sites/oliverherzfeld/2016/09/22/athletes-in-video-games-balancingpublicity-rights-and-the-first-amendment/?sh=7767005e55b3. Acesso em: 22 set. 2021.

GAVAZZA MARQUES, Erickson. Liberdade de Informação, Internet, Árbitros de Futebol e Atletas Amadores: aspectos controvertidos da comercialização das imagens do espetáculo esportivo. In: MACHADO, Rubens Approbato, et al. (Org.). Curso de Direito Desportivo Sistêmico, Editora Quartier Latin do Brasil, São Paulo, 2007.

GAGLiANO, Pablo Stolze; FILHO, Rodolfo Pamplona. Novo Curso de Direito Civil: parte geral. v. I. 4. ed. São Paulo: Saraiva, 2003.

H20. Micro Star v. FormGen Inc.. 1998. Disponível em:

https://h2o.law.harvard.edu/collages/2507. Acesso em: 22 set. 2021. 
HESSE, Konrad. A força Normativa da Constituição. Trad. Gilmar Ferreira Mendes, Porto Alegre. 1991.

IL SOLE 24 ORE. Diritti di immagine: la battaglia di Ibra contro Fifa21 e sindacato e tutti i nodi giuridici. 2020. Disponível em: https://www.ilsole24ore.com/art/dirittiimmagine-battaglia-ibra-contro-fifa21-e-sindacato-e-tutti-nodi-giuridici-AD0jqo4. Acesso em: 22 set. 2021.

JUNIOR, Walter Godoy dos Santos; AMBIEL, Carlos Eduardo Ambiel. Relação entre contrato de trabalho e contrato de licença de uso de imagem. Disponível em: https://ibdd.com.br/relacao-entre-contrato-de-trabalho-e-contrato-de-licenca-de-uso-deimagem/. Acesso em: 23 set. 2021.

MARTINS, Ives Gandra da Silva. Tratado de Direito Constitucional. v.1., $2^{a}$ ed., São Paulo: Saraiva, 2012.

MAXIMILIANO, Carlos. Hermenêutica e Aplicação do Direito. Rio de Janeiro: Renovar, 1999.

MENDES, Gilmar Ferreira. Curso de Direito Constitucional, $7^{\text {a }}$ ed., São Paulo: Saraiva, 2012.

MINISTÉRIO PÚBLICO. Declaração e Programa de Ação de Viena. 1993. Disponível em: https://gddc.ministeriopublico.pt/sites/default/files/declaracao_e_programa_acao_viena.pdf. Acesso em: 23 set. 2021.

MIRANDA, Pontes de. Tratado de Direito Privado, Tomo I: Introdução, Pessoas Físicas e Jurídicas. São Paulo: Revista dos Tribunais, 2012.

MORAES, Maria Celina Bodin de. Danos à pessoa humana. Rio de Janeiro: Renovar, 2007. MORAES, Walter. Direito à própria imagem. Doutrinas Essenciais de Direitos Humanos. Revista dos Tribunais. v. 2. ago, 2011, p. 1089 - 1117. Disponível em: 
https://www.revistadostribunais.com.br/maf/app/resultList/document?\&src=rl\&srguid=i0ad82 d9b0000017c280cf451f123f9cd\&docguid=I455e5e00629f1 1e194bf000085592b66\&hitguid=I $455 \mathrm{e} 5 \mathrm{e} 00629 \mathrm{f} 11 \mathrm{e} 194 \mathrm{bf} 000085592 \mathrm{~b} 66 \&$ spos $=2 \& \mathrm{epos}=2 \& \mathrm{td}=5 \& \mathrm{context}=22 \& \mathrm{crumb}-$ action=append\&crumblabel=Documento\&isDocFG=false\&isFromMultiSumm=\&startChunk=1\&endChunk=. Acesso em: 27 set. 2021.

NACIONES UNIDAS. Declaração sobre o Direito ao Desenvolvimento. 1986. Disponível em: https://acnudh.org/pt-br/declaracao-sobre-o-direito-ao-desenvolvimento/. Acesso em: 23 set. 2021.

ROSENVALD, Nelson. Dignidade Humana e Boa-fé no Código Civil. São Paulo: Saraiva, 2005.

ROSENVALD, Nelson; NETTO, Felipe Braga. Estudos em homenagem a Clóvis Beviláqua por ocasião do centenário do Direito Civil codificado no Brasil. In: GUERRA, Alexandre Dartanhan de Mello (Coord). São Paulo: Escola Paulista da Magistratura, 2018.

\section{SARLET, Ingo Wolfgang. Dignidade da pessoa humana e direitos fundamentais na}

Constituição Federal de 1988. 9. ed. rev. atual. Porto Alegre: Livraria do Advogado Editora, 2011.

SARMENTO, Daniel. Direitos Fundamentais e Relações Privadas. Rio de Janeiro: Lumen Juris, 2004.

SOUTAR, G., \& SWEENEY, J.C.. Valor percebido pelo consumidor: o desenvolvimento de uma escala múltipla de itens. Jornal do Varejo, 2001. p. 203-220. Disponível em: https://research-repository.uwa.edu.au/en/publications/consumer-perceived-value-thedevelopment-of-a-multiple-item-scale. Acesso em: 27 set. 2021.

\section{SPORT BIBLE. EA Were Banned From Selling FIFA Game In Germany Because Of} Oliver Kahn's Image Rights. 2020. Disponível em:

https://www.sportbible.com/football/news-ea-were-banned-from-selling-fifa-game-becauseof-oliver-kahn-20201124. Acesso em: 22 set. 2021. 
STJ - SUPERIOR TRIBUNAL DE JUSTIÇA. Agravo em Recurso Especial no 1.570.763

SP. Rel. Ministro Marco Buzzi. Agravante: Lincoln Cassio de Souza Soares; Electronic Arts Nederland B V; Electronic Arts Europe LTD. Agravado: os mesmos. Data da Publicação: 03/12/2019a.

STJ - SUPERIOR TRIBUNAL DE JUSTIÇA. Agravo de Instrumento no Recurso Especial no 1.758.467 SP. Rel. Min. Raul Araújo. Recorrente: Gonzalo Antonio Fierro Caniullan. Recorrido: Electronic Arts LTDA. Data da Publicação: 30/10/2019b.

STJ - SUPERIOR TRIBUNAL DE JUSTIÇA. Agravo de Instrumento no Recurso Especial $n^{0}$ 1.773.726 SP. Rel. Min. Moura Ribeiro. Agravante: Electronic Arts Bederland B V; Electronic Arts LTDA; Electronic Arts LTDA; Marcelo da Paixão Ramos Nicácio. Agravado: os mesmos. Data da Publicação: 21/11/2018.

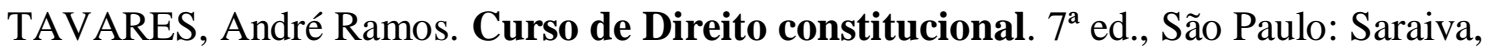
2009.

THALER, Richard. Mental Accounting and Consumer Choice. Marketing Science. 1985. p. 199-214.

THE NEW YORK TIMES. Image Rights vs. Free Speechin Video Game Suit. 2010. Disponível em: https://www.nytimes.com/2010/11/16/sports/16videogame.html. Acesso em: 23 dez. 2021.

UNITED NATIONS. Universal Declaration of Human Rights. 1948. Disponível em: https://www.un.org/en/about-us/universal-declaration-of-human-rights. Acesso em: 23 set. 2021.

WIPO. Understanding sports image rights. Disponível em: www.wipo.int/iputreach/en/ipday/2019/understanding_sports_image_rights.html. Acesso em: 23 set. 2021. 